\title{
Excision of Lipoma
}

National Cancer Institute

\section{Source}

National Cancer Institute. Excision of Lipoma. NCI Thesaurus. Code C51769.

The surgical removal of a lipoma. 